\title{
History and the Critique of Social Concepts
}

\author{
BRIAN EPSTEIN
}

Philosophy of the Social Sciences, 40, No. 1 (2010), 3-29.

Many theorists have regarded genealogy as an important technique for social criticism. But it has been unclear how genealogy can go beyond the accomplishments of other, more mundane, critical methods. I propose a new approach to understanding the critical potential of history. I argue that theorists have been misled by the assumption that if a claim is deserving of criticism, it is because the claim is false. Turning to the criticism of concepts rather than criticism of claims, I expand on the distinction between "descriptive semantics" and "foundational semantics" to show that genealogy can be uniquely qualified to explore the foundations of concepts, and hence to criticize concepts that are problematic in nonobvious ways.

Suppose a critic is concerned about some social phenomenon. She is disconcerted, say, by rehabilitation practices in Texas prisons, or by the aggressive entrepreneurial culture of Silicon Valley, or by the admiration of contestants in “America's Top Model” for Tyra Banks even as she belittles them. The critic suspects that such phenomena are oppressive, whether or not that oppression is evident to the players involved.

To unearth potential oppression, suppose the critic looks into the history of the phenomena in question. For example, she might examine the evolution of approaches to prisoner rehabilitation, testing the hypothesis that actual rehabilitation practices were developed on the basis of public relations value rather than for the good of the prisoners. In showing that the origin of the practice was dubious or deplorable, the critic aims to vindicate her suspicion and undermine the practice, with its history providing an argument for its revision. 
Can history accomplish this? Suppose the critic does demonstrate that a belief originated deplorably. Does that support her critical aims, or is it irrelevant to them?

In this paper, I discuss some unrecognized ways that "genealogical" arguments $^{1}$ are uniquely qualified for social criticism. In doing so, I will raise doubts about certain other uses of genealogy that some theorists put stock in. In most applications, genealogies are not much different from other techniques for coming up with evidence in support of a critical hypothesis. But I will argue that genealogy can have interesting and distinctive critical potential. Because theorists have failed to deflate the more mundane uses of genealogy, this potential has been obscured.

In section I, I discuss three ways history has been used and discussed for critical purposes. I suggest that none captures a particularly distinctive role for genealogy. In section II, I propose a turn from the critique of claims to a focus on the critique of concepts and words, and suggest that genealogy be applied where criticism is deserved despite the fact that a claim employing the word or concept may be true. In section III, I build on an externalist approach to concepts and words to lay the groundwork for a positive theory. I propose a number of distinctions for clarifying various elements of "foundational semantics," focusing in particular on the elements that are essential to the determination of meaning. In section IV, I apply the analysis

* My thanks to Mark Risjord, Alison Wylie, and the participants at the Philosophy of Social Science Roundtable 2009, to Simon May and Bill Fitzpatrick, and to three anonymous reviewers.

${ }^{1}$ In this paper, I will ride a bit roughshod over the distinctions between various approaches to the use of historical investigation in criticism. Foucault, for instance, contrasts genealogy with "archaeology," where the latter stresses the investigation of rule-governed systems of thought and discourse in historical periods, while the former stresses the contingency of historical development, and Nietzsche contrasts traditional history with "wirkliche Historie." I will not be concerned with describing sharp boundaries among these, and will speak of genealogy, genetic arguments, and criticism using historical investigation, more or less interchangeably. 
of foundational semantics to historical grounds for criticism. I propose two ways that words and concepts can have "rotten" foundations, and hence may deserve criticism even if used in true and non-oppressive claims. These both may offer unique critical roles for genealogy. In section V, I conclude with directions for future investigation.

\section{History in critique}

Any application of history to social criticism must be sensitive to the "genetic fallacy." Although the fallacy was only articulated in recent years, it has long been understood to be a significant problem for the social critic's use of history. ${ }^{2}$ Wesley Salmon has given its most influential statement. The genetic fallacy is, as he puts it, "the fallacy of considering factors in the discovery, or genesis, of a statement relevant, ipso facto, to the truth or falsity of it." ${ }^{3}$ Suppose for instance that our critic, on investigating the evolution of beliefs about rehabilitation, does find that they were put in place for deplorable reasons. That does not itself serve as criticism of those beliefs. It may just be a case of our prisons having been given historical lemons, and yet made social lemonade. Just because they developed for deplorable reasons, they need not be oppressive in the present, or what for short I will call "vicious."

${ }^{2}$ Cf. Crouch (1993)

${ }^{3}$ Salmon (1984), p. 12. Salmon credited the clarification of the fallacy to Reichenbach's distinction between the "context of discovery" and the "context of justification." Whether Salmon takes the distinction differently from Reichenbach is discussed in Nickles (1980). Following Kuhn's work on scientific revolutions, this distinction has been questioned by a number of philosophers of science, largely in defense of including historical factors in scientific justification. I think it is easy to overstate the extent to which this distinction has been erased. While it is surely true that factors in scientific discovery cannot be disentangled from the justification of scientific claims, it is important not to take every miscellaneous historical fact in a scientific discovery to be germane to its justification. This point becomes even more important in avoiding what below I call the "context fallacy," in connection with the individuation of concepts. 
Perhaps an even clearer way of putting the problem is as a "genetic dilemma": for critical purposes, history is either (a) irrelevant or (b) redundant. Suppose some phenomenon originated deplorably. The phenomenon may be vicious, i.e., oppressive features may still persist into the present. Or it may not. (a) Suppose the phenomenon is not vicious. Despite being developed out of an oppressive past, the phenomenon has not developed to be itself oppressive. In this case, revealing oppression in the past is at best irrelevant and at worst misleading. (b) Suppose on the other hand that it is vicious. Then the historical origins may not be misleading. But they are superfluous for criticism of the phenomenon. Since the oppressive features persist presently, they can be found by examining society synchronically, rather than having to rely on a historical examination. A deplorable history, in short, is irrelevant (and potentially misleading) if the phenomenon is not vicious, and redundant if it is. Better not to bother with the history.

\subsection{Some plausible uses of history}

There are a number of plausible responses to this. ${ }^{4}$ Consider, for instance, Gary Gutting's defense of Foucault's methodology. He begins with Foucault's own characterization of genealogy:

'Historical beginnings are lowly: not in the sense of modest or discreet like the steps of a dove, but derisive and ironic, capable of undoing every infatuation'...To provide a genealogy is 'to identify the accidents, the minute deviations - or, conversely, the complete reversals - the errors, the false appraisals, and the faulty calculations

\footnotetext{
${ }^{4}$ Salmon also notes two acceptable uses of history in criticism: "The genetic fallacy needs to be treated with care, because there are times that an aspect of a statement's genesis can in fact be pertinent to its truth or falsity: (i) A connection between the method of a claim's development and the likelihood that it is true, or (ii) The statement itself may involve an assertion about its own genesis." Salmon (1984), p. 15. These fall into my roles (2) and (1) below.
} 
that give birth to those things that continue to exist and have value for us. ${ }^{5}$

Gutting then raises and rejects the application of the genetic fallacy in the following way:

It may seem that this critical use of genealogy falls into the genetic fallacy, arguing from the lowly origin of something to its lack of value... It is not, however, the genealogist who introduces the question of origins. This is done when, for example, the Ten Commandments are said to have moral authority because God handed them to Moses on Mount Sinai, or when the subordination of women is said to be required by their biological nature... Genealogical critique will avoid the genetic fallacy as long as it is directed at efforts to support established authorities on the basis of their origin. This understanding of genealogy is implicit in Foucault's claim that it reveals the contingency of that which was said to be necessary. Here, necessity (due to divine will, human nature, or transcendental conditions of possibility) is the general category under which fall all efforts to justify practices and institutions in terms of their privileged origin. ${ }^{6}$

Taking off from this passage, we can identify three roles for history in criticism that avoid the genetic fallacy or dilemma:

\section{Confirming or undermining a claim that is explicitly or tacitly historical}

Genealogy can reveal that a claim directly depends on a historical claim, such as originating in God's orders. If a belief being criticized directly involves or implies a historical claim, such as "Lincoln was shot in Ford's Theater," then clearly historical investigation is pertinent to the criticism.

Sometimes such cases can be subtle, especially when a claim involves a concept that has historical application conditions. For something to be a

\footnotetext{
${ }^{5}$ Gutting (2005), p. 49, citing Foucault (1977), pp. 144-146.

${ }^{6}$ Gutting (2005), p. 50.
} 
footprint, for instance, requires that it have been marked in the past. So we can refute the claim, That mark is a footprint, by investigating the actual genesis of the mark. Elsewhere I have called properties like being a footprint "initiated" properties, and have noted that a great many social properties e.g., being married, being owned, having a name, and being legitimate - fall into this category. ${ }^{7}$ For a government to be legitimate, for instance, may require that it have been chosen through some democratic practice. If so, then the claim, That government is legitimate, is tacitly a claim about history, and it may be confirmed or refuted through historical investigation.

\section{Providing evidence to justify or undermine a non-historical claim}

History may also provide evidence for the truth-value of a claim or undermine its justification, even if the claim is not itself historical. Suppose, for instance, we find that some congressional district is gerrymandered. Perhaps we think that is a good thing, because the gerrymandering is claimed to buttress the rights of minorities. Investigating the history, we might find that gerrymandering was in fact introduced to limit power of certain minorities in the district. For instance, we might find that historically gerrymandering was employed to consolidate the votes of a predominantly black urban population, so that they control $90 \%$ of the votes for the congressman in one district but then fail to get $51 \%$ in a number of other districts. Here, the role of history is to obtain empirical evidence about the real motivations and consequences of a policy. It might spark a certain suspicion, especially if the policy was introduced by people with suspect goals. Historical examination thus may be a way to break through cognitive limitations on understanding the present.

A related way history can provide evidence is by revealing deeply hidden motivations. One argument frequently criticized as a simple instance of the genetic fallacy is Freud's discussion of the origin of the concept of God.

7 That is, a concept that has historical conditions for it application, among others. Cf. Epstein (2008). 
Freud gives an account in Totem and Taboo of the development of the notion of God from the earlier use of totems as father-surrogates. ${ }^{8}$ The claim that this is a simple genetic fallacy is the following: even if this is the original motivation for man's belief in God, that has no impact on whether our current beliefs are well-grounded.

But on the other hand, if Freud's account is true, it may serve as evidence that even today our beliefs are motivated similarly. This may serve to undermine the grounds for our own belief in God, if we presently have such a belief.

\section{Revealing real alternatives}

A third use of genealogy arises from the historical demonstration that a practice or institution is contingent, rather than necessary. Gutting, in the passage above, argues that the demonstration of contingency is relevant to criticism because it helps reveal hidden justifications. But that is the same as the point in the previous subsection. In fact, there is another role that has been widely discussed for the critical utility of demonstrating contingency.

In his 1958 essay "History and the Social Sciences," Fernand Braudel notes that studying the past allows us to distance ourselves from or "defamiliarize" the present:

There is no society, however primitive, that does not bear the "scars of events."... Live in London for a year, and you will not know much about England. But, by contrast, in light of what has surprised you, you will suddenly have come to understand some of the most deepseated and characteristic aspects of France, things which you did not know before because you knew them too well. With regard to the present, the past too is a way of distancing yourself. ${ }^{9}$

In his own historical investigations, Braudel works to reveal elements of social structures that may be unfamiliar to the agents living in a society. But

\footnotetext{
${ }^{8}$ Freud (1913/1950), p. 183.

${ }^{9}$ Writing, evidently, for a French audience. Braudel (1958), pp. 36-37.
} 
even without the baggage of "structure," the idea is that history can be evidence for revealing peculiarities of an agent's own situation she might be unable to see directly.

Defamiliarizing the methods we use to rehabilitate criminals, for instance, not only makes them salient to us, but prompts us to consider that there may be viable alternatives to those methods. Where we might have taken our rehabilitation practices to be natural or necessary, it enables us to see different possibilities and hence to open our practices to criticism.

\subsection{Why be dissatisfied with the three existing roles?}

As far as they go, these are fine roles for historical investigation in social criticism. Even role (1) has some real critical power, when it goes unrecognized the extent to which social claims involve historical conditions. At the same time, this sort of critique is fairly obvious, and the history in question is not the history or genealogy of a claim, but rather the historical truth-conditions of the claim.

Roles (2) and (3) do involve genealogical investigation. But for both, genealogy is on a par with other means for criticism, and what genealogy contributes can be accomplished by other means. They provide no special role for genealogy. Role (2) may be particularly useful if there is a paucity of contemporary evidence. But on the other hand, the sorts of phenomena that are criticized with genealogies, like punishment or morality, are often ones for which there is a good deal of evidence. If there is some obstacle to finding out true motivations for a belief, as in the Freudian case, then perhaps good evidence is hard to uncover. But again it is unclear why historical evidence is not just on a par with all other evidence.

As for role (3), although defamiliarization can generate powerful results, there are a number of reasons it is not a particularly striking role for genealogy. First, defamiliarization plays only an indirect role in criticism. Demonstrating contingency or raising to salience does not directly serve to criticize a practice. After all, with enough scrutiny we can render any feature of society, even the good ones, salient or peculiar. To criticize a practice requires more. 
Second, while using the past may be a good way to make real alternatives salient, the fact that the alternative is in the history of the actual concept is beside the point. As Braudel himself points out in the above passage, the defamiliarization performed by studying the past parallels the defamiliarization performed by investigating a different culture. Crosscultural comparison may serve the goal just as well as historical examination, and thought experiments or artificially constructed possibilities may also do as well, or even better. ${ }^{10}$

Third and most seriously, in the above roles, it is not clear why the ignominy of the origin of some phenomenon should be relevant at all. Even if investigating history does serve to defamiliarize some phenomenon, it is unclear why the fact that the history is deplorable matters. Only for role (2) does the fact that a history is deplorable even come into the picture. And the benefit it provides there is only that it may cue a recognition that the current justification is deplorable as well. While all three roles for genealogy accomplish something, they leave it unclear whether there is any distinctive role genealogy plays in criticism. ${ }^{11}$

Below I will argue that in fact these three roles give short shrift to the critical potential of genealogy, and that Foucault, among others, deserves

${ }^{10}$ A historically accurate account or an accurate cross-cultural account has the advantage that it unequivocally demonstrates the possibility of a human society before the phenomenon in question developed, by giving an actual case. But there may be such enormous discrepancies between our culture and the contrasting one that such demonstrations may not do much to show that given other features of our situation, the phenomenon is indeed contingent. Thinking it through in a thought-experiment might well be better for showing real alternatives.

${ }^{11}$ As applied to Foucault in particular, they may not even spare his actual histories from accusations of the genetic fallacy. It is often not clear that the histories he gives do perform any of the above roles, or that they are any more than detailed developmental narratives. Even the care and texture with which he describes historical development sometimes does the critical work a disservice, since it is unclear whether most of the texture does anything to demonstrate contingency or undermine justifications. 
some credit for moving towards a more ambitious goal than the above roles represent.

\section{Critical potential and the turn to concepts}

Genealogy is nothing more than a critical tool, and it is possible that it is only a minor weapon in the critic's arsenal. The attention it has been given by critical theorists, however, suggests that they at least have believed it to have a certain potential for cracking otherwise recalcitrant problems.

In The Idea of a Critical Theory, Raymond Geuss discusses a number of states a society might be in, in which members of a society are oppressed or suffering. The most troubling case is the "nightmare" scenario in which members of a society "are actually content with their situation, but only because they have been prevented from developing certain desires which in the 'normal' course of things they would have developed, and which cannot be satisfied within the framework of the present social order." ${ }^{12}$ In such a situation, members of a society successfully pursue ends that are contrary to their real interests, believing, reasoning, and acting in ways that reinforce their own oppression. This sort of situation has been a persistent worry for social critics, since it means that valid criticism may be unable to take hold.

It is not obvious this sort of nightmare ever occurs, or is even possible. The Orwellian fears of some mid-century theorists seem to have overestimated the malleability of the human psyche and the ability of oppressive regimes to modify desires and reasoning. Where there has been brutal repression, the suffering population has in general been painfully aware of its suffering. What's more, suffering people often have a correct theory of its source, even if they have lacked the means to overthrow it. Fears of the more hidden sorts of control discussed by Adorno and Horkheimer have not

aged well either. Today their views on popular culture seem dated and elitist,

${ }^{12}$ Geuss (1981), p. 83. 
and their warnings about the corporate control of rationality itself seem shrill. $^{13}$

But even if these fears are overstated, they may still be relevant. There may not in fact be totalizing systems of control that give a single explanation for the thought and behavior patterns of a population. Nonetheless, it can hardly be doubted that on smaller scales, phenomena much like the nightmares are common. People are regularly influenced to hold beliefs and conduct themselves in ways that are contrary to their own interests. It is easy to come up with a list of candidates: the NRA persuading the rural poor that gun rights are of such paramount importance that they overlook issues that serve their greater economic and social interests; certain sects using religion as a means of social control; some "liberalized" sexual behaviors reinforcing gender inequity in high school; girls being influenced to prefer magazines with drastically retouched photographs. These do not rise to the level of "nightmare" of a total ideology, which conditions the agents' desires and reasoning. Nonetheless, the resistance of these beliefs to critique shares some features with the nightmare scenario, such as being self-reinforcing and having critical rhetoric "co-opted" by the dominating group. ${ }^{14}$

Furthermore, even without "nightmares," the critical techniques that were meant to address them may be of value. If critical theorists, for instance, have indeed managed to develop techniques for breaking out of nightmare scenarios, even a bit, then these techniques may have critical potential in less dramatic cases.

\subsection{Turning to concepts}

Why have some theorists taken genealogy to have the potential to accomplish this? I want to pursue an idea that has roots in Nietzsche, Adorno, and Foucault. The idea involves understanding the nightmare

${ }^{13}$ E.g., Horkheimer and Adorno (1972), Adorno (1973).

14 For instance, when clothing manufacturers use the language of feminism and “empowerment” in advertising. 
scenario somewhat differently than Geuss does. As described by Geuss, the nightmare scenario has two characteristics. One, the beliefs and desires of agents are contrary to their interests, and two, the agents' being in that state is a matter of those beliefs and desires having been generated in coercive or otherwise abnormal circumstances. That is, what the agents are resistant to revise is their deluded propositional attitudes (i.e., their beliefs, desires, etc.), and the reason they have deluded attitudes is that they were caused by conditions of coercion. It is obvious how a genealogy of those attitudes might seem to address this. ${ }^{15}$ But I suggest that neither of these two is the key problem.

The insight - which has roots in Nietzsche, Adorno, and Foucault - is that the error of the deluded agents is not in their propositional attitudes. The critical problem is not the epistemologist's problem, i.e., that there may be obstacles to the revision or improvement of beliefs if agents start out in some problematic epistemic or practical state. Instead, the error lies in the concepts that the agents possess, the material out of which thoughts and propositions are cast.

Many people hold that when we find a statement objectionable or worthy of rejection, its problem lies in its not being true. Sally Haslanger, for instance, has recently argued for an approach to ideology critique using the idea of "relative truth." 16 On her approach, ideologically objectionable

${ }^{15}$ Habermas, for instance, considers the role genealogy can play in revealing when attitudes necessarily originated in coercive circumstances. (E.g., in Habermas and Luhmann (1971), pp. 101ff.) It is unclear, however, how the move to an actual history of coercion to the impossibility of being derived noncoercively can demonstrate that an attitude is deluded. Or conversely, how in fact being derived noncoercively guarantees that an attitude is not deluded. It seems likely that it can guarantee legitimacy, but not freedom from delusion.

${ }^{16}$ Haslanger suggests diagnosing the case using recent work in semantics on faultless disagreement and "relative truth.” Kölbel (2003); MacFarlane (2003); Richard (2004); Lasersohn (2005). Garcia-Carpintero and Kölbel (2008) has a number of useful papers and references. 
statements are diagnosed as involving a clash between being true when assessed in one milieu and false when assessed in another.

The case she considers involves a dispute between a parent and her seventh-grade daughter about wearing a shirt that exposes the girl's midriff, which the parent rightly believes contributes to the inappropriate sexualizing of young girls. The question is what exactly the problem is with the daughter's claim, "But Mom, you're just wrong. Everyone knows that croptops are cute; and I don't want to be a dork." ${ }^{17}$ Haslanger's strategy is to address the fact that the mother and daughter seem sincerely to contradict one another. Acknowledging that the daughter and her friends have the authority in their milieu to determine the extensions of 'cute' and 'dorky', Haslanger works to show that the claim "crop-tops are cute" can come out true when assessed in the daughter's milieu but false in the mother's milieu. She suggests that social criticism may serve the role of defending the mother's assessment context - and thus assessing the claim as false - as being preferable.

A similar issue arises in some recent treatments of racial epithets. Christopher Hom, for instance, has argued that statements employing racial epithets, such as "Yao Ming is a chink" are false, claiming that the epithets in fact have empty extensions. ${ }^{18}$ Stephen Neale and Kent Bach have independently proposed "multiple proposition" accounts of the semantics of epithets, in which users of the epithets typically assert true primary propositions and false secondary propositions. ${ }^{19}$ Each of these accounts understands the reason that claims involving racial epithets are objectionable as being their assertion of falsehoods.

Without going into detail on these, I want to advance a different approach. Focusing on truth or falsity may be misleading, for discerning the problems with such claims. The statements "crop-tops are cute" or "Yao

\footnotetext{
${ }^{17}$ Haslanger (2007)

${ }^{18}$ Hom (2008)

${ }^{19}$ Bach (1999); Neale (1999); Neale (2001)
} 
Ming is a chink” surely deserve to be criticized, but not because they are false. Instead, the problem lies in aspects of the objectionable concepts cute and chink apart from their extensions. David Kaplan pithily describes this view as holding that "Truth is immune to epithetical color." 20 Despite being true, statements or thoughts may deserve criticism, when something is objectionable about the words or concepts themselves.

Excessive association of critique with rooting out falsehood is, I believe, a pervasive and longstanding hindrance in considering genealogy. If we aim to criticize objectionable statements, we often waste our time if we look for arguments, historical or otherwise, aimed at undermining their justification. Instead, I propose that where genealogy is uniquely suited for criticism is in unrooting what sorts of problems there can be with words and concepts, even when claims made with them are true.

\subsection{Concepts and the three above roles for history}

On its own, shifting from the critique of beliefs to the critique of concepts does not eliminate the threat of the genetic and related fallacies. Consider an argument such as Freud's about the development of the concept of justice. In Group Psychology and the Analysis of the Ego, he says that justice is a product of childhood envy: "If one cannot be the favorite oneself, at all events nobody else shall be the favorite." 21 This is a crude genealogy of justice, and presumably is a product of Freud's imagination. But even if he were correct that the concept of justice did develop from envy, that would still fail to be grounds for criticism. Again, we may simply have made lemonade from lemons.

Here the genetic fallacy as applied to the concept envy is not much different from a genetic fallacy as applied to a belief. And in fact, in parallel to the roles for history in criticizing beliefs, there are equally mundane roles for history in criticizing concepts.

${ }^{20}$ Kaplan (1999), p. 6.

${ }^{21}$ Freud (1949 [1921]), p. 120. 
As with beliefs, let us call a concept 'vicious' when its uncritical employment perpetuates oppression. Paralleling role (2) for beliefs, historical examination may also be used as evidence of viciousness of a concept. For instance, suppose that justice not only originated in envy, but the descriptive analysis of justice involves envy, and that the employment of justice involves envious feelings. Showing that the concept of justice originated with envy could serve as evidence that those feelings of envy are present today as well.

There is also a role for history in conceptual criticism that parallels role (3), defamiliarizing the present or bringing out "real alternatives." The Frankfurt School in particular was concerned with the revelation of "objectification errors," i.e., the error of taking a concept that is an outcome of social relations to be "objective."22 Just as the past may be used to make a familiar set of beliefs or practices salient and make their contingency evident, it also may be used to reveal the contingency of a particular concept, particularly when a similar but interestingly different one is employed in the past. The same sources of dissatisfaction with roles (1)-(3) as applied to belief apply to these roles of history in criticizing concepts. Using historical evidence is fine, but it is just evidence to reveal synchronic problems. And as with beliefs, bringing out "real alternatives" is not unique to the past, nor does it make use of the fact that a concept's history was deplorable. Whether or not the origin of a concept was deplorable, what matters for its criticism is whether the concept is prone to generating falsehoods or perpetuates oppression, and whether it can be replaced with an improvement.

\subsection{Investigating how concepts are constituted}

Genealogy as applied to concepts can fall prey to the same fallacy and can successfully be employed in the same roles as the critique of beliefs. So how does the turn from beliefs to concepts carve out a new role for genealogy? The distinctive role for genealogy comes out when we see how historical

22 A reasonable way of understanding "objective” in this sense is an outcome of human nature and physical facts about the world, as opposed to an outcome of contingent ways a society is structured. 
factors can be constitutive of concepts themselves, not just causes for why concepts have arisen. To clarify this, we will need to make progress on how concepts are constituted, and in particular how they can be ontologically founded on historical factors.

I will approach social concepts from an externalist perspective, taking concepts and word-meanings to be determined by external factors in the world, not just by the conceptions that we associate with them. ${ }^{23}$ The beliefs of a society about the concepts they employ do not exhaust their meanings, and the entire community of speakers can be mistaken, sometimes radically, about their concepts. Thus a correct descriptive analysis of a concept may diverge substantially from an analysis of the conception a community associates with a concept.

Externalism admits that environmental, social, and other non-mental factors can figure into the individuation of our concepts. And historical factors can play a particularly important role. This will account for genealogy being uniquely suited for certain types of criticism.

But we should be cautious, since is easy to infer too much from externalism. There are limits to which external factors are genuinely constitutive of concepts, and which are simply extraneous detail. In some historical analyses of concepts, it is common to fall prey to what we might call the "context fallacy": Concept $\mathrm{x}$ is employed in context $\mathrm{C}$, and thus the important features of $\mathrm{C}$ are relevant to the analysis of $\mathrm{x}$. That inference is obviously mistaken. The Nazis, for example, had the concept paperweight, and they spoke of them and used them in their practices. But of course it would be absurd to think that Nazism is relevant to the analysis (and

${ }^{23}$ A number of people have also taken this approach. Haslanger, in (Haslanger (2005); Haslanger (2006), contrasts descriptive analysis with the analysis of the conceptions that we associate with our concepts, as well as with the project of improving our concepts. Putnam discusses social kinds a bit in Putnam (1975), but the examples are problematic. For other work on externalism and social kinds, see also Kornblith (1980); Abbott (1989); Boyd (1999); Millikan (1999); Mallon (2003). 
criticism) of the concept paperweight. ${ }^{24}$ We need to be careful to distinguish those factors that figure into the analysis of a concept (or into its individuation, as I will discuss in a moment) from those that are extraneous detail.

\section{Toward a positive theory}

Recent semantic theory provides a germ of an idea for seeing how genealogy can be a potent source of criticism. In the following section, I present these beginnings, and propose a number of new distinctions to make progress on how we can understand the factors involved in the determination or individuation of concepts. ${ }^{25}$

In the subsequent section, I will use this analysis to raise two new ways that genealogy can figure into the criticism of concepts. First, genealogy can be required even to know what the semantic value of a term is. And second, genealogy can reveal that a word or concept is what I will call "rotten" - it may be essentially deplorable in ways that do not show up in its semantic value at all. This second point is a tentative but potentially far-reaching basis for genealogy to criticize concepts.

\subsection{Foundational semantics}

Robert Stalnaker points out that semantic theory consists of two different investigations. One is to give the semantic values of expressions of a

${ }^{24}$ Only the crudest forms of holism explicitly commit this error, but some social critics tracing the "social matrix" in which concepts are embedded fail to be sensitive to the problem. See Fodor and LePore (1992) for criticism of this and subtler related problems with conceptual analysis. See also Haslanger's careful distinction between concepts that are causally socially constructed and ones that are constitutively socially constructed, in Haslanger (2003).

${ }^{25}$ In the following, I will talk about the semantics of terms, as opposed to concepts. A more careful treatment of the relation between the individuation of concepts and of words is relevant to the present discussion, but would take us too far afield. In the present discussion, I will flip between words and concepts without careful qualification. 
language, and to explain how the semantic values of complex expressions are a function of their parts. ${ }^{26}$ This is the task of "descriptive semantics." According to the new theory of reference, the semantic value of a proper name is just the individual the name refers to. ${ }^{27}$ If that theory is correct, descriptive semantics as applied to the name 'Aristotle' will just identify the person Aristotle as the term's referent. And for a kind term like 'water', descriptive semantics identifies the natural kind water as its semantic value.

Foundational semantics, on the other hand, asks: "what is it about the situation, behavior, or mental states of a speaker that makes it the case that a particular proper name [or other expression], as used by that speaker in a particular linguistic community, has the semantic value that it has?”28 For instance, it would answer a question such as: in virtue of what does a particular utterance u (e.g., my utterance of the token Aristotle at 11am on May 31, 2009) have the semantic value it has (e.g., the person Aristotle)? A "causal" or "baptism-transmission" theory of reference ${ }^{29}$ provides one answer: it is in virtue of the initial baptism of Aristotle with the name 'Aristotle', and the subsequent transmission of the term from speaker to speaker in the linguistic community, until it reaches me. For an utterance of 'water', a baptism-transmission theory of foundational semantics will hold that it has its semantic value in virtue of the original ostensive introduction of the term with actual samples of water in the environment, and the subsequent transmission from speaker to speaker, up to the utterer.

For present purposes, I will remain neutral about which descriptive and foundational theories are correct. But I do want to distinguish some different

26 The "semantic value" of an expression is generally defined as the feature of the expression that contributes to determining whether a sentence in which it occurs is true or false. It is often understood as a more precise way of speaking of an expression's "meaning," reasonably narrowly construed.

${ }^{27}$ Kripke (1972/1980)

${ }^{28}$ Stalnaker (1997), p. 535.

${ }^{29}$ Kripke (1972/1980); Evans (1973). 
parts of foundational semantics that tend to be run together. Let me begin with an example.

Consider a particular utterance, as when Ashley says during recess, "Caitlin is a dork." Let us assume that for a term like 'dork', the semantic value is just the social kind $\mathrm{K}$ to which the word 'dork' refers, ${ }^{30}$ where the kind is fully characterized by its application conditions. These may just be a long disjunctive set of traits or behaviors that pre-teens dislike: $x$ is a dork just in case $x$ wears pants that are too short or $x$ wears pants that are too long or $x$ wears track suits or $x$ never wears cut-off shirts or $x$ gets good grades, etc. That is the descriptive semantics of 'dork'.

The foundational semantics of 'dork' involves much more. Foundational semantics is not usually treated in a particularly organized way. This has obscured the many separate roles that historical and other external factors play in determining the semantic value of an utterance or in the individuation of a thought. To disaggregate and organize all the aspects of the foundational semantics of 'dork', I will construct a matrix, setting two different dimensions against one another: (A) the components of foundational semantics, and (B) the different roles played by factors within each component. I will fill in examples as I construct the matrix.

Dimension (A): The components in determining the semantic value of an utterance. As is clear from the name "baptism-transmission," there is a difference between the part of foundational semantics that treats the fixing of reference in the first place, and the part that treats the transmission from person to person. But this is not the only distinction to be made. Apart from the factors that determine that a word has the semantic value it does, there are factors that determine that the word is the word it is. And there is also a

${ }^{30}$ I do not insist that this is the correct analysis of the semantic value of a social term like 'dork'. But one outcome of the present discussion is that even if the semantic value of 'dork' is understood as no more than a function from worlds to extensions, a proper understanding of its foundational semantics can explain how when it is uttered other aspects of the word come in. 
distinction between the factors that connect a speaker with a word, and the factors that make a particular utterance a token of a word. We can break down the parts of foundational semantics along dimension A into:

(A1) Semantic value of word: The factors in virtue of which the word (rather than the utterance) has the semantic value that it does. Examples of such factors for the word 'water' are: that the word was introduced by ostension, and that the demonstrated sample was composed of $\mathrm{H}_{2} \mathrm{O}$.

(A2) Word identity: The factors in the virtue of which the word is the word that it is, apart from its having the semantic value that it does. Examples of such factors for 'water' are: that it was introduced as having the phonetic structure /'wotər/ or the string ' $\mathrm{w}^{\prime} \wedge^{\prime} \mathrm{a}^{\prime} \wedge^{\prime} \mathrm{t} \mathrm{t}$ ' ${ }^{\prime} \mathrm{e} \mathrm{e}^{\prime} \wedge$ ' $\mathrm{r}$ '.

(A3) Speaker participation in word: The factors in virtue of which the speaker knows (or participates in) the word. Examples for 'water' as possessed by a speaker are: the transmission from the dubber to the dubber's daughter; from her daughter to her daughter's son, and on down to the speaker.

(A4) Utterance identity: The factors in virtue of which a particular utterance by the speaker is a token of the word. Examples for 'water' as uttered are: that the speaker had the intention of uttering a word, that the intention was appropriately connected to the causal chain involving 'water', etc.

Applying these to 'dork', we can break down factors involved in foundational semantics into categories, in Table 1: 
Table 1:

\begin{tabular}{|c|c|c|}
\hline 'dork' & What is determined & $\begin{array}{l}\text { Factors involved in the } \\
\text { determination }\end{array}$ \\
\hline (A1) Semantic value & $\begin{array}{l}\text { The fact that the word 'dork' has } \\
\text { semantic value K }\end{array}$ & $\begin{array}{l}\text { The actual historical hierarchy-reinforcing } \\
\text { practices in middle schools, fashion trends } \\
\text { promoted by Madison Ave., etc. }\end{array}$ \\
\hline (A2) Word-identity & $\begin{array}{l}\text { The fact that 'dork' has } \\
\text { phonetic-structure [dork], is a } \\
\text { word in English, and any other } \\
\text { non-semantic essential } \\
\text { properties of the word }\end{array}$ & $\begin{array}{l}\text { The first utterance of the term, the actual } \\
\text { ostensive act of dubbing, the phonetic space } \\
\text { of the English language }\end{array}$ \\
\hline $\begin{array}{l}\text { (A3) Speaker participation } \\
\text { in word }\end{array}$ & $\begin{array}{l}\text { That Ashley knows (participates } \\
\text { in) the word 'dork' }\end{array}$ & $\begin{array}{l}\text { Particular causal chain of transmission from } \\
\text { dubber to Ashley }\end{array}$ \\
\hline (A4) Utterance tokening & $\begin{array}{l}\text { That Ashley uttered a token of } \\
\text { 'dork' at t }\end{array}$ & $\begin{array}{l}\text { Ashley's intention at t, the acoustic blast } \\
\text { uttered }\end{array}$ \\
\hline
\end{tabular}

All of these together are parts of the complete story that explains why Ashley's utterance has the semantic value it does. Distinguishing (A1) through (A4) points out that different factors, external and internal, do different things in determining the semantic value of the utterance.

Within each component, however, a different set of distinctions needs to be made as well. The basic idea is in accomplishing a step (A1) or (A2) or (A3) or (A4), the external and internal factors can be broken down into those that are essential, those that are involved but inessential, and those that are extraneous. This is dimension (B).

To explicate this dimension a bit, consider for example (A3), the factors determining that Ashley knows the word 'dork'. Let us take it as a given that the word 'dork' has been introduced, say by malevolent middle-schoolers in the 70s. Then to get to Ashley's own knowledge of the word, on a causal theory of reference, the explanation is that there is a causal network of transmission from Ashley back to those students.

It is important to note, however, that not every feature of the causal chain is on a par. Some features are entirely extraneous - they are causally connected to Ashley, but do not explain why Ashley counts as knowing the word. Moreover, even if we consider the actual causal factors that do explain Ashley's knowledge of 'dork', that particular causal chain is not essential to 
the fact that Ashley participates in 'dork'. What is essential is that there be some causal chain connecting Ashley in the right way back to the baptizers. Each of the steps (A1)-(A4) thus breaks down along a second dimension:

Dimension (B): The different roles for factors in the components of determining semantic value.

(B1) Grounds, which may or may not be essential: The fact Ashley is a user of the word 'dork' is grounded by the particular causal chain stretching from the 70s middle-schoolers to their acquaintances and on down to Ashley. The causal chain is the thing in virtue of which Ashley is a user of the word 'dork'. ${ }^{31}$

(B2) Generic foundations: Although the fact that Ashley is a user of 'dork' is grounded by a particular causal chain, there could have been other causal chains that grounded that fact. What I will call the "generic foundations" of the fact Ashley is a user of 'dork' is not the particular causal chain, but the generic fact that there is a causal chain satisfying such-and-such properties. ${ }^{32}$ The reason this is crucial is that only this generic fact will be necessary or essential to the word, rather than contingent. This matters for distinguishing which aspects of history are relevant to criticism.

(B3) Miscellany: This is a catch-all category for all factors that are causally involved in making something the case, without qualifying as

\footnotetext{
${ }^{31}$ The notion of a ground is playing an increasingly prominent role in the metaphysics of objects and facts. See in particular Fine (2001); Correia (2005). It is meant to pin down the idea that $\mathrm{X}$ consists of nothing more than $\mathrm{Y}, \mathrm{X}$ is the case in virtue of $\mathrm{Y}$, that $\mathrm{Y}$ explains why $\mathrm{X}$ is the case, or that $\mathrm{Y}$ determines that $\mathrm{X}$ is the case, each of these being understood as a "tight metaphysical" relation rather than a causal or pragmatic relation.

${ }^{32}$ I take the idea of generic foundations from Correia.
} 
grounds. The fact that the middle-schools in question are, say, in the New

York area, is a miscellaneous fact in the narrative explaining why Ashley

is a user of 'dork'.

In table 2, the factors involved in determining (A1)-(A4) are broken down into this second dimension:

Table 2:

\begin{tabular}{|c|c|c|c|c|}
\hline 'dork' & $\begin{array}{l}\text { What is } \\
\text { determined }\end{array}$ & (B1) Grounds & $\begin{array}{l}\text { (B2) Generic } \\
\text { Foundations } \\
\end{array}$ & (B3) Miscellany \\
\hline $\begin{array}{l}\text { (A1) Semantic } \\
\text { value }\end{array}$ & $\begin{array}{l}\text { That the word } \\
\text { 'dork' has semantic } \\
\text { value K }\end{array}$ & $\begin{array}{l}\text { The actual historical } \\
\text { hierarchy-reinforcing } \\
\text { practices in middle } \\
\text { schools, fashion } \\
\text { trends promoted by } \\
\text { Madison Ave., etc. }\end{array}$ & $\begin{array}{l}\text { That the historical } \\
\text { practices are } \\
\text { hierarchy-reinforcing, } \\
\text { that the trends are } \\
\text { sexualizing }\end{array}$ & $\begin{array}{l}\text { What Caitlin is } \\
\text { wearing, what } \\
\text { school Ashley and } \\
\text { Caitlin attend, etc. }\end{array}$ \\
\hline $\begin{array}{l}\text { (A2) Word- } \\
\text { identity }\end{array}$ & $\begin{array}{l}\text { That 'dork' has } \\
\text { phonetic-structure } \\
\text { [dork], is a word in } \\
\text { English, and any } \\
\text { other non-semantic } \\
\text { essential properties } \\
\text { of the word }\end{array}$ & $\begin{array}{l}\text { The first utterance of } \\
\text { the term, the actual } \\
\text { ostensive act of } \\
\text { dubbing, the phonetic } \\
\text { space of the English } \\
\text { language }\end{array}$ & $\begin{array}{l}\text { That the first utterance } \\
\text { tokened the phonetic- } \\
\text { structure [dork], that } \\
\text { the word was } \\
\text { introduced by an } \\
\text { English speaker }\end{array}$ & $\begin{array}{l}\text { The place and time } \\
\text { that the word was } \\
\text { dubbed, the } \\
\text { etymology of the } \\
\text { word, etc. }\end{array}$ \\
\hline $\begin{array}{l}\text { (A3) Speaker } \\
\text { participation in } \\
\text { word }\end{array}$ & $\begin{array}{l}\text { That Ashley knows } \\
\text { (participates in) the } \\
\text { word 'dork' }\end{array}$ & $\begin{array}{l}\text { Particular causal } \\
\text { chain of transmission } \\
\text { from dubber to } \\
\text { Ashley }\end{array}$ & $\begin{array}{l}\text { That there was a } \\
\text { causal chain of } \\
\text { transmission from } \\
\text { dubber to Ashley }\end{array}$ & $\begin{array}{l}\text { The ages and } \\
\text { locations of the } \\
\text { speakers } \\
\text { transmitting the } \\
\text { word, etc. }\end{array}$ \\
\hline $\begin{array}{l}\text { (A4) Utterance } \\
\text { tokening }\end{array}$ & $\begin{array}{l}\text { That Ashley } \\
\text { uttered a token of } \\
\text { ‘dork' at t }\end{array}$ & $\begin{array}{l}\text { Ashley's intention at } \\
\text { t, the acoustic blast } \\
\text { uttered }\end{array}$ & $\begin{array}{l}\text { That Ashley and the } \\
\text { acoustic blast satisfied } \\
\text { the appropriate } \\
\text { tokening conditions }\end{array}$ & $\begin{array}{l}\text { The audience of } \\
\text { Ashley's utterance, } \\
\text { etc. }\end{array}$ \\
\hline
\end{tabular}

For the social critique of concepts, several roles thus emerge for historical factors in the constitution of concepts, many of which do not appear in a descriptive analysis at all.

It is crucial to distinguish the miscellaneous factors from the grounds from the generic foundations. Neglecting this is the source of endless confusion in historical criticism. Only by stripping away the miscellaneous factors, and potentially also the grounds that are not generic foundations, can 
the historical criticism of concepts can avoid errors like the "context fallacy." When some factor is a generic foundation of a concept, the concept can potentially be criticized on the basis that the concept carries along these factors when it is employed. But miscellaneous factors, like the fact that paperweights were used by Nazis, are only parts of a historical narrative that are irrelevant to critique.

\section{History and foundational semantics}

In each of the boxes in table 2, there may be both synchronic and historical factors. An obvious case is box (A3B1), the grounding of the fact that Ashley knows the word 'dork'. If a causal theory of reference is correct, then that fact's grounds are the causal chain stretching back to the originators of the term.

The generic foundations of Ashley's knowledge of 'dork' involve historical factors as well, not the particular causal chain stretching back from Ashley, but historical facts nonetheless. For instance, the historical fact that that there is some causal chain satisfying appropriate conditions that stretches from Ashley back to the originators of 'dork'. In other words, it is essential to the fact that Ashley knows the word 'dork' that that historical fact is in place. This is one of the historical facts that necessarily ontologically determines that her utterance "Caitlin is a dork" has the semantic value it does.

The causal chain is the most obvious place history figures into foundational semantics. But it is not the only place, nor is it the key one for getting genealogical criticism going. The historical foundations of (A1), the word having the semantic value it does, and of (A2), the word being the word it is, are more germane to conceptual criticism.

\subsection{Two ways genealogy can serve in conceptual criticism}

With the above distinctions, two new ways emerge for genealogy to figure into the criticism of concepts. The first is an immediate consequence of the generic foundations of semantic value involving historical factors, and is closely connected to Saul Kripke's discussion of the "necessary 
aposteriori” and Hilary Putnam's justly famous if peculiar example of robotcats. $^{33}$ Simply put, genealogy can be required even to know what the semantic value or meaning of a term is. ${ }^{34}$

A second and potentially even more interesting role can also arise, even if we already know a term's semantic value. When historical factors are among the foundations of a term - especially the generic foundations - there is a sense in which they are a part of the word as it is used, even when not part of the word's descriptive semantics. This, finally, is the place where the fact that a word's history is deplorable might actually matter. A word might not show it, and yet be "rotten" in its foundation.

\section{When history is required for determining semantic value}

In Naming and Necessity Kripke discusses the theoretical identification "Water is $\mathrm{H}_{2} \mathrm{O}$," arguing that if this statement is true, it is necessarily true, but that the fact that it is true may only be knowable aposteriori. ${ }^{35}$ The reason (using my above terminology) is that the semantic value of the term 'water' is generically founded in the structure of the sample with which it was ostensively introduced. It has that semantic value whether or not the people introducing the term knew anything about the structure of that kind, and thus it can require empirical investigation to know that fact.

Many of the cases of proper names that Kripke discusses also show this. To know an identifying description of the referent of a term, it may be required that we trace back the historical chain of transmission to the person to whom the term was attached. ${ }^{36}$ Putnam's discussion of cats is similar, and makes it still clearer that the empirical investigation required must often be historical. For instance, the proposition "Some cats are furry," entails the

${ }^{33}$ Kripke (1972/1980) Putnam (1962)

${ }^{34}$ See note 26 above.

${ }^{35}$ Cf. Soames (2003); Soames (2006) for discussion of the philosophical implications of this.

${ }^{36}$ In particular, the cases of Gödel, Moses, and Jonah highlight this. 
proposition, "Some biological creatures are furry,” but it might take historical investigation to ascertain that.

Knowledge is often easy to acquire. I know on testimony, for instance, that the referent of the term 'Aristotle' was a Greek philosopher, and I do not need to trace back the history in order to know it. Even when history is involved in determining semantic value, we do not necessarily need historical investigation in order to know what the semantic value is. But especially with social kinds the tracing of history can be required in order to obtain correct descriptions of their semantic values.

To return to the case we began with, consider the predicate 'rehabilitated criminal'. This predicate is complex, and it is not obvious what the correct descriptive analysis is. The project of giving a descriptive analysis would normally begin by investigating the conceptions we associate with it, and probing our intuitions about its extension. We might also try to balance these intuitions with our prior beliefs about how the term ought to be systematized, to arrive at a reflective equilibrium. But it is the foundational factors that determine the predicate's semantic value, not the conceptions we have of it. However irregular the boundaries of the predicate, it is the foundational factors that determine that those boundaries - the application conditions of the predicate - are what they are.

Externalism implies that there can be a gap between the conceptions that we attach to a term and the correct descriptive analysis of it. It is only through the investigation of external factors that we can determine the correct descriptive analysis. In order to determine what the semantic value of 'rehabilitated criminal' is, historical investigation may thus be required. ${ }^{37}$

\section{Rotten foundations}

The fact that historical factors figure into the generic foundations of a word introduces another intriguing way that words can deserve criticism.

${ }^{37}$ I discuss a variety of related cases in Epstein (2006). 
Unlike all the other forms of genealogical criticism, it explains how the fact that a word's history is deplorable can be directly relevant to its criticism.

Call a word "rotten” if its generic foundations are deplorable. First I will consider when the generic foundations of the word having the semantic value it does [i.e., the factors in box (A1B2)] are deplorable. In this case I will call the word "semantically rotten." Then I will consider when the generic foundations of the word being the word it is [i.e., the factors in box (A2B2)] are deplorable. In this case I will call the word "otherwise rotten."

The foundational semantics - and particularly the generic foundations of social terms, is almost entirely unexplored terrain. For the present purposes, I will have to give some simplified examples to illustrate the point. Consider again Freud's case of justice and envy. Freud's proposal that justice is a product of childhood envy, as I pointed out, fails to imply that the concept is vicious. But in light of the constitutive role that foundational factors can play, if Freud is right then things may nonetheless not be altogether copacetic for justice.

On an externalist account, particular feelings of envy may be grounds for 'justice' having the meaning it does. Suppose that 'justice' was introduced ostensively, involving instances of envious feelings. The people introducing the term pointed to cases of agents making decisions on the basis of their envious motivations, saying: "These are the prototypical cases in which justice is served.” To the baptizers of 'justice', those envious feelings were not apparent. Yet those envious feelings may not just be miscellaneous historical factors that caused us to dub 'justice' as we did. Instead, if it is indeed the features of the situations they pointed at which figure into determining the meaning of 'justice', then aspects of those situations may be among the generic foundations of 'justice'.

In this case the term 'justice' is semantically rotten. When 'justice' is employed in an assertion, these deplorable factors are not just accidental historical accompaniments, but are in part constitutive of the assertion. ${ }^{38}$

${ }^{38}$ Or equivalently, they may essentially figure into the individuation of the concept justice. 
A similar account might be given of the predicate 'rehabilitated criminal'. When our critic finds that it has a deplorable history, that alone does not serve as a basis for criticizing it. Except if she finds that 'rehabilitated criminal' is semantically rotten, i.e., that deplorable features of history are essential ontological determinants of the fact that the term has the semantic value it does.

Falsehood, I suggested above, is not the only basis for criticizing beliefs or thoughts or statements. When a word is used, it is not only its contribution to the truth value of the proposition expressed that may be the basis for criticism. When a word is used, it is the word, with all its essential properties, that is part of the utterance. In considering the use of an objectionable concept or word, the problem may be with factors apart from its semantic value and the generic foundations of the semantic value.

\subsection{What is wrong with rotten concepts?}

Two different words may have the same semantic value, and yet one may be rotten and the other not. Suppose that a word $\mathrm{w}_{1}$ has semantic value justice and is generically founded in laudable historical facts, while word $\mathrm{w}_{2}$ has the same semantic value, and yet is generically founded in deplorable historical facts. Those deplorable historical facts are essential properties of $\mathrm{w}_{2}$ : they are part of what makes $\mathrm{w}_{2}$ the word it is. When $\mathrm{w}_{2}$ is used in an utterance, it is that word, with the deplorable essential properties it has, that is part of the utterance, whether or not the speaker is aware of it, and whether it is vicious or not. But still, if $\mathrm{w}_{2}$ is not vicious, we might wonder why rottenness is a problem at all.

It is plausible that a concept's deserving criticism should not be limited to its having oppressive consequences. Even a term's semantic value having nasty features does not entail that it is vicious. Suppose the term 'hysteric', for instance, has as part of semantic value the association of a certain kind of irrational emotion with women, and yet also suppose (counterfactually) that our society has eliminated the oppression of women, so that the term 'hysteric' is not oppressive in actual use. Nonetheless, even without oppressive consequences it seems clear that the term should be replaced. 
Likewise, the fact that a term is rotten means that it brings oppressive foundations into the utterance, even if not into the propositional content. Which on its own may also be reason for abandoning it.

Moreover, although a concept may be rotten without that rottenness cascading into the term's semantic value and use, most often a rotten concept will be vicious. And the viciousness will be explained by the fact that it is rotten. These problems generally come in packages. A term like 'justice' may be criticizable because its generic foundations manifest themselves in oppressive practices, but the deep explanation for the problem is the generic foundation for the term, i.e., the explanation for its having the meaning it does. Genealogy may be the only way to find this deep explanation.

\section{Waking the critic from her nightmare?}

Much social criticism does not require particularly penetrating methodologies. Oppression can often be discerned by casual observation, and the larger problems for social critics are most often practical ones, figuring out what features of society ought to be changed in light of competing demands and the difficulties in predicting the outcomes of social policies.

Moreover, fears of all-embracing social delusion may be misplaced. In epistemology, although worries about Descartes' demon have not entirely receded, most epistemologists have given up on the quest for knowledgeproduction procedures that promise complete immunity from error. Likewise, the social critic today is less worried about total ideological nightmares than critics once were.

Developing methods for attacking radical error, however, can have payoffs even for addressing everyday problems. Just as the quest for perfect certainty has led epistemology to insights about robust knowledge production, likewise the social theorist worried about ideological nightmares develops techniques for uncovering and criticizing social concepts in general.

I have argued that genealogy has the potential to root out problems in the foundations of the concepts we employ, even when the problems do not manifest themselves in oppression. As I suggested, critics like Adorno and Foucault did, at least implicitly, direct much of their critique to the concepts 
that we possess and employ. However, they both hammered at one issue under different names: the problem of "reification," or "objectification error," or the neglect of the "radical contingency" of categories we employ. This point is not too different from Marx's famous discussion of the "fetishism of commodities" in 1867.

But the critique of concepts, I suggest, has been ill-served by focusing excessively on this issue. It is easy to acknowledge that many of the concepts we employ are socially constructed in various ways, without regarding that as reason for criticizing them.

Among the socially constructed concepts, the critic's problem is not which concepts are contingent, but which ones are healthy and which ones are rotten. Genealogy is one critical tool for finding some sources of rottenness, that cannot be found in even an exhaustive study of society as it is at the present moment. This vindicates the intuition that genealogy can be a technique for breaking out of certain "nightmare"-like scenarios, in which social critique is obstructed regardless how much an agent reflects or investigates the world as it is.

That a concept is rotten does not force us to abandon it: there may be terms, like racial ones, that are rotten but whose use should be continued to mitigate past wrongs. Still, rottenness is a reason to consider whether we might be better served by changing our concepts.

The foregoing framework is only a beginning. Both the study of foundational semantics and of the semantics of social terms are in their infancy. And the foregoing discussion only scratches the surface of possible cases of words and concepts are plausibly "semantically rotten" or "otherwise rotten."

Possible cases of the "otherwise rotten" - i.e., having deplorable generic foundations of word-identity - may include such words as 'negro', 'colored' as opposed to 'black', and 'African American', all of which plausibly have the same semantic values and perhaps even the same generic foundations for their semantic values, but may have different generic foundations for wordidentity. The distinctions between unacceptable terms and more acceptable 
ones may lie in their semantic values, or in the generic foundations for their semantic values, or in the generic foundations for word-identity, or in some aspect of their grounds, or even simply in typical contexts of use. Knowing how to criticize concepts will depend on developing such examples, and gaining a better understanding of the elements of both the descriptive and foundational semantics of social terms.

Advances in the understanding of genealogy and historical criticism promises to go hand in hand with advances in theories of semantics and social concepts. Genealogy is just one tool in the critic's arsenal, but even the possibility that it has distinctive critical potential may serve as a entry point into a broader inquiry. 


\section{References}

Abbott, B. 1989. "Nondescriptionality and Natural Kind Terms." Linguistics and Philosophy 12: 269-291.

Adorno, T. W. 1973. Philosophy of Modern Music. New York, Seabury Press.

Bach, K. 1999. "The Myth of Conventional Implicature." Linguistics and Philosophy 22(4): 327-366.

Boyd, R. 1999. "Kinds, Complexity and Multiple Realization: Comments on Millikan's "Historical Kinds and the Special Sciences"." Philosophical Studies 95(1-2): 67-98.

Braudel, F. 1958. "History and the Social Sciences." In On History. Chicago, University of Chicago Press.

Correia, F. 2005. Existential Dependence and Cognate Notions. Munich, Philosophia Verlag.

Crouch, M. 1993. "A "Limited" Defense of the Genetic Fallacy." Metaphilosophy 24(3): 227-240.

Epstein, B. 2006. "The Nonlocality of Semantic Content," ms.

Epstein, B. 2008. "The Realpolitik of Reference." Pacific Philosophical Quarterly 89: 1-20.

Evans, G. 1973. "The Causal Theory of Names: Part I." Aristotelian Society: Suppl 47 187-208.

Fine, K. 2001. "The Question of Realism." Philosopher's Imprint 1(1): 1-30.

Fodor, J. A. and E. LePore. 1992. Holism : a shopper's guide. Oxford ; Cambridge, Mass., Blackwell.

Foucault, M. 1977. "Nietzsche, Genealogy, History." In Language, CounterMemory, Practice: Selected Essays and Interviews. D. F. Bouchard, Ed. Ithaca, Cornell University Press.

Freud, S. 1913/1950. Totem and Taboo. New York, W.W. Norton. 
Freud, S. 1922. Group Psychology and the Analysis of the Ego. London, The International Psychoanalytical Press.

Garcia-Carpintero, M. and M. Kölbel, Eds. 2008. Relative Truth. Oxford, Oxford University Press.

Geuss, R. 1981. The Idea of a Critical Theory. Cambridge, Cambridge University Press.

Gutting, G. 2005. Foucault. Oxford, Oxford University Press.

Habermas, J. and N. Luhmann. 1971. Theorie der Gesellschaft oder Sozialtechnologie - Was leistet die Systemforschung? Frankfurt, Suhrkamp.

Haslanger, S. 2003. "Social Construction: The "Debunking" Project." In Socializing Metaphysics. F. Schmitt, Ed. Lanham, MD, Rowman and Littlefield.

Haslanger, S. 2005. "What are we Talking About? The Semantics and Politics of Social Kinds." Hypatia 20(4): 10-26.

Haslanger, S. 2006. "What Good are our Intuitions? Philosophical Analysis and Social Kinds." Supplementary Proceedings of the Aristotelian Society 80(1): 89-118.

Haslanger, S. 2007. "'But Mom, Crop-Tops are Cute!" Social Knowledge, Social Structure, and Ideology Critique." Philosophical Issues 17(1): 70-91.

Hom, C. 2008. "The Semantics of Racial Epithets." Journal of Philosophy CV(8).

Horkheimer, M. and T. W. Adorno. 1972. Dialectic of enlightenment. New York, Seabury Press.

Kaplan, D. 1999. "What is Meaning? Explorations in the Theory of Meaning as Use," ms.

Kölbel, M. 2003. "Faultless Disagreement." Proceedings of the Aristotelian Society 104: 53-73. 
Kornblith, H. 1980. "Referring to Artifacts." Philosophical Review 89: 109114.

Kripke, S. 1972/1980. Naming and Necessity. Cambridge, Harvard University Press.

Lasersohn, P. 2005. "Context Dependence, Disagreement, and Predicates of Personal Taste." Linguistics and Philosophy 28(6): 643-686.

MacFarlane, J. 2003. "Future Contingents and Relative Truth." Philosophical Quarterly 53: 321-36.

Mallon, R. 2003. "Social Construction, Social Roles, and Stability." In Socializing Metaphysics. F. Schmitt, Ed. Lanham, MD, Rowman and Littlefield: 327-353.

Millikan, R. G. 1999. "Historical Kinds and the "Special Sciences"." Philosophical Studies 95: 45-65.

Neale, S. 1999. "Coloring and Composition." In Philosophy and Linguistics. R. Stainton, Ed. Boulder, Westview Press: 35-82.

Neale, S. 2001. "Implicature and Colouring." In Paul Grice's Heritage. G. Consenza, Ed. Rome, Brepols: 135-180.

Nickles, T. 1980. Scientific Discovery, Logic, and Rationality. Dordrecht, D. Riedel.

Putnam, H. 1962. "It Ain't Necessarily So." In Philosophical Papers. Cambridge, Cambridge University Press. 2.

Putnam, H. 1975. "The Meaning of 'Meaning'." In Philosophical Papers. Cambridge, Cambridge University Press. 2.

Richard, M. 2004. "Contextualism and Relativism." Philosophical Studies 119: 215-242.

Salmon, W. C. 1984. Logic. Englewood Cliffs, N.J., Prentice-Hall. 
Soames, S. 2003. Philosophical Analysis in the Twentieth Century. Princeton, Princeton University Press.

Soames, S. 2006. "The Philosophical Significance of the Kripkean Necessary Aposteriori." Philosophical Issues 16: 288-309.

Stalnaker, R. 1997. "Reference and Necessity." In A Companion to the Philosophy of Language. B. Hale and C. Wright, Eds. Oxford, Blackwell: 534-554. 